\title{
The effects of monocusp valve implantation and transannular patch angioplasty on pulmonary regurgitation and right ventricular failure after total correction of tetralogy of fallot
}

\author{
Mahmoud Samadi ${ }^{1}$, Masoum Khoshfetrat ${ }^{2}$, Aliakbar Keykha ${ }^{3}$, Sayeh Haj Javadi ${ }^{4},{ }^{*}$
}

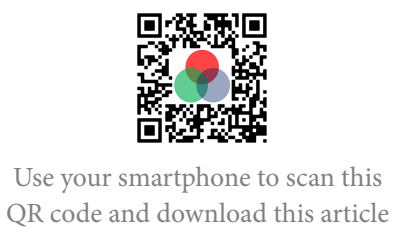

${ }^{1}$ Department of Paediatric Cardiology, School of Medicine, Tabriz University of Medical Sciences, Tabriz, Iran

${ }^{2}$ Department of Anaesthesiology and Critical Care, Khatam-Al-Anbiya Hospital, Zahedan University of Medical Sciences, Zahedan, Iran

${ }^{3}$ Department of Nursing, School of Nursing and Midwifery, Mashhad University of Medical Sciences, Mashhad, Iran

${ }^{4}$ Department of Paediatrics, School of Medicine, Tabriz University of Medical Sciences, Tabriz, Iran

Correspondence

Sayeh Haj Javadi, Department of Paediatrics, School of Medicine, Tabriz University of Medical Sciences, Tabriz, Iran

Email: sa.hajjavadi@gmail.com

History

- Received: Mar 06, 2020

- Accepted: May 11, 2020

- Published: May 26, 2020

DOI : 10.15419/bmrat.v7i5.607

\section{Check for updates}

\section{Copyright}

( ) Biomedpress. This is an openaccess article distributed under the terms of the Creative Commons Attribution 4.0 International license.

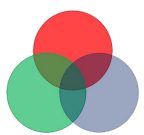

\begin{abstract}
Background: Pulmonary regurgitation (PR) is often known as an acquired condition after surgical correction of tetralogy of Fallot (TOF). Therefore, the present study aimed to compare the use of monocusp valve (MV) implantation and transannular patch (TAP) angioplasty on PR and right ventricular (RV) failure following surgery to repair TOF. Methods: This prospective randomized clinical trial $(\mathrm{RCT})$ was performed on a total number of 60 patients undergoing reconstructive surgery on TOF. For this purpose, TAPs without and with monocusp reconstruction were used in Group I ( = 30 patients) and Group II ( $n=30$ patients), respectively. Then, echocardiographic parameters, mortality rates, and clinical data from pediatric intensive care unit (PICU) were evaluated during a follow-up period for both groups. Results: Out of the 60 patients undergoing surgery and evaluated, 39 individuals were male $(65 \%)$ and the rest were female $(n=21$ patients, $35 \%)$. No significant difference was observed in terms of age, body weight, body surface area (BSA), mortality rate, and ejection fraction (EF) between the two study groups. The findings revealed that the number of patients with severe PR was higher in the group receiving TAP angioplasty. Furthermore, the difference between the two groups with regards to severity of PR was significant $(p=0.012)$. Conclusion: It was concluded that MV reconstruction of TOF is effective in reducing pulmonary artery (PA) and pulmonary valve (PV) insufficiency.

Key words: Tetralogy of Fallot, Pulmonary Regurgitation, Transannular Patch, Congenital Heart Disease, Right Ventricular Failure, Monocusp Reconstruction
\end{abstract}

\section{BACKGROUND}

Tetralogy of Fallot (TOF) is known as a congenital heart disease (CHD) impairing oxygen delivery to the tissues. It includes four types of defects that often occur together, i.e., overriding aorta, pulmonary stenosis, ventricular septal defect (VSD), and right ventricular hypertrophy $(\mathrm{RVH})^{1,2}$. Former surgical procedures to correct this congenital anomaly have been thus far accompanied by a large right ventriculotomy to close ventricular septal defect (VSD) and pulmonary stenosis, resolved through transannular patch enlargement (TAPE) ${ }^{3,4}$. However, today, ventriculotomy is less commonly exercised to close VSD; other methods such as transarterial VSD closure and transarterial right ventricular outflow tract (RVOT) resection or patch plasty, together with transarterial transpulmonary repair, have been developed ${ }^{5}$. One of the important advantages of TAP is that it immediately leads to RV hypertension reduction as RVOT can usually grow proportionally with a child ${ }^{6,7}$. Nevertheless, TOF reconstruction with a TAP can induce post-surgery pulmonary regurgitation (PR). There- fore, reduction in cardiac output due to early RV dysfunction poses a myriad of problems for these patients. However, this is not the only cause of early morbidity and mortality after surgery. Indeed, other factors such as age and weight at the time of surgery, surgeons' skills, use of TAP, duration of surgery, and cardiopulmonary bypass ( $\mathrm{CPB}$ ) time may also have impact ${ }^{8-10}$. Despite advances and further developments of novel techniques in this field, long-term mortality and PR are still at high rates in patients undergoing TAP repair ${ }^{11}$. To diminish volume overload, even for a short time after surgery, some studies have recommended implanting a monocusp valve $(\mathrm{MV})^{12-14}$. Theoretically, a monocusp patch can mitigate patch-related PR although long-term results might not be satisfactory, especially in younger children ${ }^{15}$. Accordingly, this work aimed to evaluate the results of two surgical approaches exercised for total repair of TOF, including MV implantation and TAP angioplasty on pulmonary artery (PA) insufficiency and RV failure.

Cite this article : Samadi $M$, Khoshfetrat $M$, Keykha $A$, Javadi $S$. The effects ofmonocusp valveimplantation and transannular patch angioplasty on pulmonary regurgitation and right ventricular failure after total correction of tetralogy of fallot. Biomed. Res. Ther.; 7(5):3799-3806. 


\section{METHODS}

After review and approval from the Vice-Chancellor's Office for Research and Technology and the Ethics Committee of Tabriz University of Medical Sciences, Iran, as well as receival of the code of ethics (IR.TBZMED.REC.1397.311), this prospective randomized clinical trial (RCT) was performed. The study was conducted between March 2011 and March 2018 , on a total number of 60 patients referred to Shahid Madani Hospital (city of Tabriz) for surgical repair of TOF. The patients were first visited by a pediatric cardiologist and a pediatric cardiac surgeon. Then, echocardiography and routine lab tests were performed to confirm the diagnosis and to determine the inclusion criteria. Upon obtaining informed consent from their parents, the patients who met the inclusion criteria were randomized into two groups. Regarding the informed consent, a written consent form was obtained after explaining the benefits and the complications of each surgical procedure. For the purpose of randomization of patient selection, corresponding to the estimated sample size, 60 cards with two different colors (30 green cards and 30 orange cards) were prepared and then respectively arranged in a black box. After referring the patients for surgery, a card was randomly selected from the box. Accordingly, the patients could be assigned to Group I if the card was green, or to Group II if the card was orange. As well, RVOT resection included reconstruction by TAP in Group I. In Group II, it entailed reconstruction by TAP plus monocusp ventricular outflow patch (MVOP) valve repair. The sample size was set at 60 in accordance with previous studies; it was determined to be 30 patients for each group based on the formula for calculating the sample size with $95 \%$ confidence interval (CI) and $80 \%$ test power ${ }^{16}$.

\section{Inclusion criteria}

The inclusion criteria were children aged 1-10 years, parental consent to perform elective surgical procedures, normal blood coagulation indices, and moderate pulmonary annular hypoplasia with z-score ranging from -2 to -3 .

\section{Exclusion criteria}

Patients with mental retardation, pulmonary failure, pulmonary infection or acute respiratory distress syndrome (ARDS), pulmonary atresia, discontinuous pulmonary arteries, as well as those undergoing previous palliative procedures and TOF with an atrioventricular septal defect (AVSD) were excluded from this study.
The sample selection process is shown in Figure 1. In the operating room, the patients were examined by an anesthesiologist who was unaware of their placement in the study groups and who determined the amount of anesthetic drugs. The drugs were injected by the anesthetic nurse and the patients were intubated by the anesthesiologist. The arterial catheter was inserted accordingly into the radial artery by an anesthesiologist and the arterial pressure was monitored. The central venous catheter was also fixed through the internal jugular vein. Cardiac monitoring for all patients began and continued throughout the surgery. Subsequently, the surgical procedure started via midsternotomy incision. Soft tissue incision and bleeding control were further continued with an electrocauter until the heart was exposed and then percutaneous balloon pericardiotomy was done. Following heparin injection, $3 \mathrm{~g} / \mathrm{kg}$ activated clotting time (ACT) increased up to $450 \mathrm{sec}$ onds. At this time, aorto-bicaval cannulation was conducted and CPB was connected to the patients. Cold blood cardioplegia was also completed and it was repeated every $25 \mathrm{~min}$. After that, mild-tomoderate hypothermia induction was performed (28 $-30^{\circ} \mathrm{C}$ ). Then, the band around the superior and inferior vena cava right atriotomy was tightened and RVOT obstruction was resolved by cutting the septal and parietal muscle bundles. Vertical pulmonary arteriotomy was also performed to ensure complete resection of the obstructing bundles. VCD closure was correspondingly fulfilled with a cortex patch using monofilament polypropylene (PP) 0.6 continuous sutures. Ultimately, the right ventricular outlet was reconstructed by two approaches:

- Group I: TAP was created with a patch of autologous pericardium treated with $0.6 \%$ glutaraldehyde for $12 \mathrm{~min}$ (each side up in the solution for $6 \mathrm{~min}$ ) and the main PA (MPA) angioplasty was performed with the prepared patch using 70 continuous PP sutures.

- Group II: MV (i.e., one-way valve) with the cortex of $0.1 \mathrm{~mm}$ was created. Then, angioplasty was done with pericardial TAP via 7 - 0 continuous sutures.

Both surgical procedures were fulfilled by the same surgical team. After stabilizing hemodynamic conditions and reversing the effects of heparin with protamine sulphate, the patients were weaned from CPB. Direct measurements of pressure were also used to rule out residual pressure gradients between RV and $\mathrm{PA}$, and the ratio between $\mathrm{RV}$ and $\mathrm{LV}$ pressures (RVP/LVP ratio) of $30-35 \mathrm{mmHg}$ was accepted. The patients were then transferred to the PICU. 


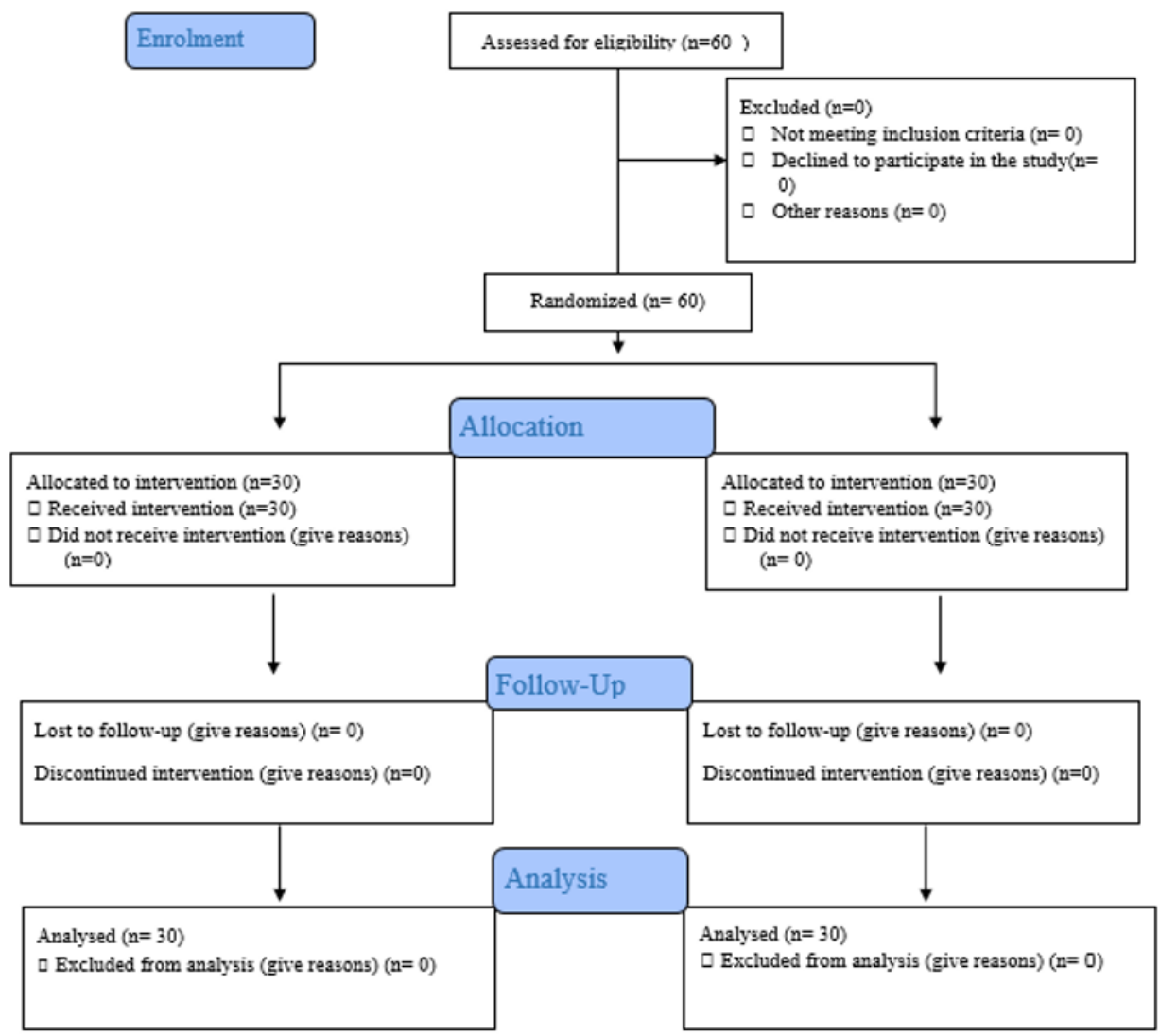

Figure 1: CONSORT flow diagram of the study. Sixty patients entered the study and were randomly divided into twogroups. Reconstructive surgery was performed in two methods. Patients werefollow up for six months and finally, the results of all patients were analyzed.

\section{Post-operative critical care and follow-up}

In the ICU, all the patients were visited twice daily by the anesthesiologist, pediatric cardiac surgeon, and pediatric cardiologist. Full monitoring and mechanical ventilation were also performed. Inotropic and sedative medications were additionally administered if needed. In the absence of hemorragia, and presence of good hemodynamic conditions, improved consciousness and respiratory status, based on the approval of an anesthesiologist, the sedation of the patients was discontinued. Patients were then hyperoxygenated for $2 \mathrm{~min}$ and the endotracheal tube was removed using suction. Oxygen administration was done with mask $(7 \mathrm{~L} / \mathrm{min})$ until no further need was assured. After extubation, the patients were evaluated using Visual Analogue Scale (VAS) and a diclofenac suppository was used to alleviate pain if needed.

Early post-operative echocardiography (24 h after surgery) was done to evaluate the outcome of surgery and cardiac function of the patients. The data were then recorded for comparisons between both groups. The early outcomes were duration of mechanical ventilation as well as length of PICU stay, mortality, and morbidity. Following the improvement of the general condition of the patients and approval by all three physicians, the patients were transferred to the cardiac surgery ward and discharged after two days. After discharge, all the patients received monthly followup twice by a pediatric cardiologist for clinical examinations, chest X-rays, echocardiography, and administration of medications if needed. At the end of the 6th month follow-up, an echocardiography was performed and data were recorded for comparisons between the two study groups.

\section{Study outcomes}

PR (none, mild, moderate, and severe), RV failure (fractional area change (FAC) less than $40 \%$ and 
tricuspid annular plane systolic excursion (TAPSE) lower than $10 \mathrm{~mm}$ were also considered as more than mild RV failure), ejection fraction (EF), and morbidity were evaluated after 6 months.

\section{Statistical analysis}

The data were analyzed using the IBM Statistical Package for Social Sciences (SPSS), version 22. Independent-sample t-test was also employed to compare the means of both quantitative variables. To compare proportions between two qualitative parameters, Chi-square $\left(X^{2}\right)$ test was subsequently utilized.

\section{RESULTS}

The study population consisted of 39 male (65\%) and 21 female $(35 \%)$ patients. The basic patient characteristics showed no statistically significant differences between the two groups. These comparison data with reference to surgical approaches are shown in Table 1. Furthermore, there was no statistically significant difference in pre-operative PVA $z$-score $(p=0.263)$ or PA index (PAI) $(\mathrm{p}=0.220)$ between the two study groups. Additionally, no significant difference was observed in CPB time and aortic cross-clamp time between both groups. However, duration of mechanical ventilation was significantly different between the two groups (the mean number of days for PICU stay in Group I was significantly higher than that in Group II). In general, the mean duration of ICU stay was low in Group I and there was no significant difference between both groups (Table 1).

\section{Post-operative results and echocardiographic data}

The findings revealed that no deaths had occurred during or after surgery until hospitalization. In primary post-operative echocardiography of the patients, PV velocity in Group I and Group II was $2.0 \pm$ $0.5 \mathrm{~m} / \mathrm{sec}$ and $1.5 \pm 0.1 \mathrm{~m} / \mathrm{sec}$, respectively; this difference was not statistically significant $(\mathrm{p}=0.249)$. In terms of echocardiography, $24 \mathrm{~h}$ after surgery, $18 \mathrm{pa}-$ tients in Group I had severe PR while 12 patients had moderate PR. In Group II, all the patients were also affected with mild PR. Besides, no statistically significant difference was observed in PR grades between the two groups $(\mathrm{p}=0.781)$.

Follow-up echocardiography, performed six months later, demonstrated that in the group with MV implantation, the severity of PA insufficiency was mild in 17 patients $(56.7 \%)$, moderate in 8 patients $(26.7 \%)$, and severe in 1 patient (3.3\%). Moreover, 4 patients (13.3\%) had no PR. In the group undergoing TAP angioplasty, the severity of PA insufficiency was mild in
7 patients (23.3\%), moderate in 8 patients $(26.7 \%)$, and severe in 9 patients (30\%). In 6 patients $(20 \%)$ of this group, no PR was observed. The difference between both groups in terms of severity of PV insufficiency was significant $(p=0.012)$ (Figure 2). No PV stenosis was reported in patients.

Accordingly, most of the patients with MV angioplasty had moderate PR, while severe PR was very high in the TAP group.

In Group I, 6 patients had an EF of less than 50\%, while EF was above $50 \%$ in 24 patients. In Group II, 7 patients had an EF of less than $50 \%$, while it was above $50 \%$ in 23 patients. A comparison of left ventricular (LV) EF using the Chi-square $\left(X^{2}\right)$ test did not show significant differences between both groups $(p=0.912)$ (Figure 3).

As illustrated in Figure 3, EF was low in a small number of patients in both groups; EF in other patients was acceptable.

In Group I, 3 patients had moderate RV failure but 1 patient in Group II suffered from this dysfunction. Moreover, there was no significant difference between both groups $(\mathrm{p}=0.510)$.

Furthermore, 1 and 2 patients lost their lives in Groups I and II, respectively.

No statistically significant differences were observed between the two groups ( $\mathrm{p}=0.312)$ (Figure 4). According to Figure 4, few patients in both groups died. There was also no difference between mortality rates in the two groups.

\section{DISCUSSION}

The results of this study demonstrated that TOF reconstruction via MV implantation could effectively mitigate PA insufficiency and severity. However, in the short term, it failed to affect RV functioning. Consistent with the results of the present study, other investigations have reported that the use of MV insertion could improve patient outcome by reducing early $\mathrm{PR}^{17,18}$. However, the major issue causing many complications in TOF patients is increased RV volume overload. If surgical procedures reduce the incidence rate of this complication, it will improve patient outcome.

Different surgical procedures, such as MV reconstruction with autologous pericardium or polytetrafluoroethylene, have thus far been suggested to prevent complications. This corrective surgical technique can moderate RV workload by lowering the degree of $\mathrm{PR}^{19,20}$. In a study by Jang et al., using a method similar to that utilized in the present study, applying MV implantation with TAP angioplasty compared 


\begin{tabular}{lccc} 
Table 1: Basic patient characteristics & & & \\
\hline Variable & Group I (n=30) & Group II (n=30) & P-value \\
\hline Gender (male/female) & $16 / 14$ & $23 / 7$ & 0.123 \\
Age & $4 \pm 2.259$ & $3 \pm 2.74$ & 0.601 \\
Body weight (kg) & $14.23 \pm 3.794$ & $12.43 \pm 4.014$ & 0.223 \\
Body surface area (BSA) (m ${ }^{2}$ ) & $0.22 \pm 0.04$ & $0.21 \pm 0.09$ & 0.258 \\
PV diameter (mm) & $4.7 \pm 1.2$ & $4.3 \pm 1.2$ & 0.594 \\
Z-score of PV diameter & $-2.2 \pm 0.4$ & $-2.7 \pm 0.7$ & 0.263 \\
PAI & $185.9 \pm 98.1$ & $176.1 \pm 89.7$ & 0.220 \\
MPA size (mm) & $5.6 \pm 2.1$ & $5.0 \pm 1.01$ & 0.285 \\
Pre-operative RVOT pressure gradient (mmHg) & $59.93 \pm 7.114$ & $62.17 \pm 5.052$ & 0.328 \\
$\begin{array}{l}\text { Post-operative } \quad \text { RVOT } \\
\text { (mmHg) }\end{array}$ & $22.12 \pm 4.1$ & $24 \pm 3.08$ & 0.147 \\
CPB (min) & gradient & & \\
Aortic cross-clamp time (min) & $161.67 \pm 12.612$ & $184 \pm 12.594$ & 0.805 \\
Ventilation duration (h) & $121.67 \pm 6.315$ & $124.70 \pm 5.861$ & 0.521 \\
Mean ICU stay (days) & $49.30 \pm 13.134$ & $12.7 \pm 6.068$ & 0.005 \\
\hline
\end{tabular}

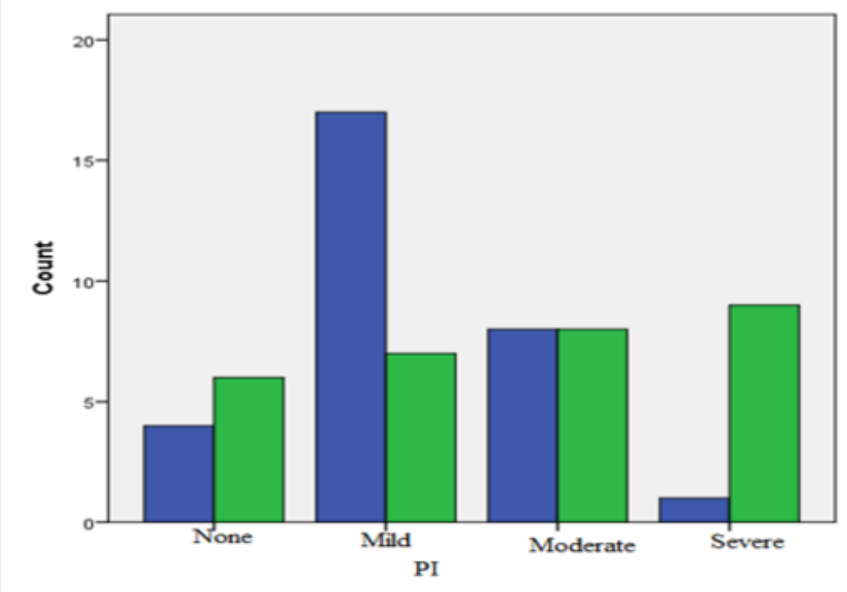

Monocusp valve Transannular patch

Figure 2: Comparison of PR grades instudy groups. Patients who underwent Transannular patch repair surgery had a higher rate of severe pulmonary artery regurgitation.

with TAP alone could delay the grade 3-4 PR. Also, $\mathrm{PV}$ stenosis was not observed in patients ${ }^{16}$. Besides, no PV stenosis was reported at the 6-month followup echocardiography in the present study, although this was not a sufficient time for careful examinations and provision of definitive comments. However, the follow-up of the patients in the study by Jang et al. lasted nearly 10 years and, thus, the results from that study could be more reliable ${ }^{16}$.
Contrary to the results of the present study, other investigations have also revealed that classification and loss of mobility have been observed in a significant number of patients at one year post-surgery ${ }^{16,21}$. Additionally, the results of other studies have shown the significant incidence of valvular insufficiency and/or obstruction $^{16,17,21,22}$. These studies found that MV insertion could cause significant complications and lead to poor patient outcomes. In the post-operative 


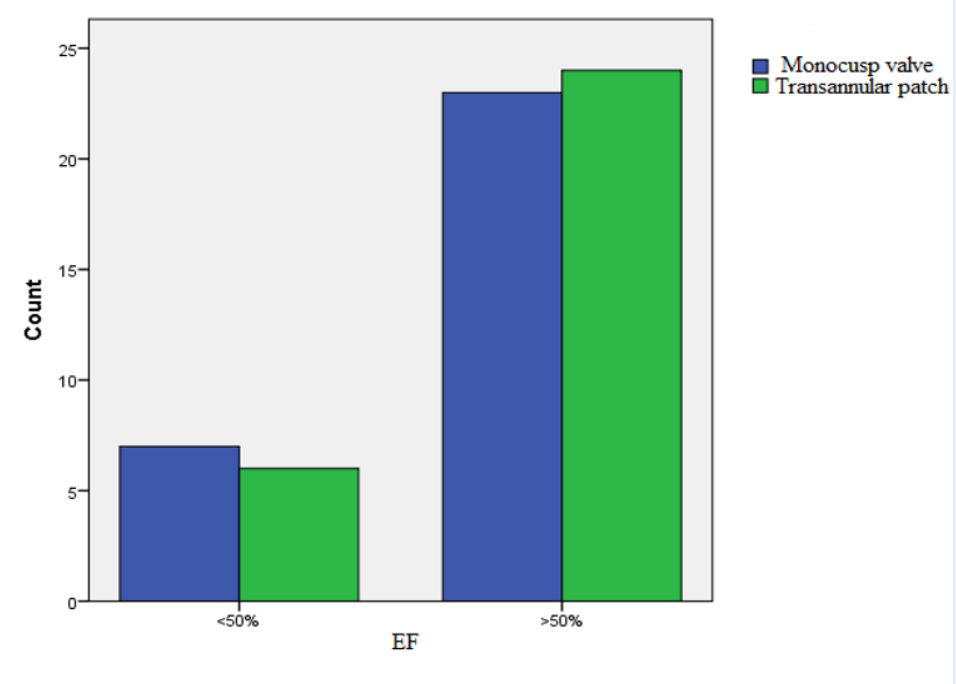

Figure 3: Comparison of ejection fraction in study groups. The effect of both surgical procedures on patients' ejection fraction was good.

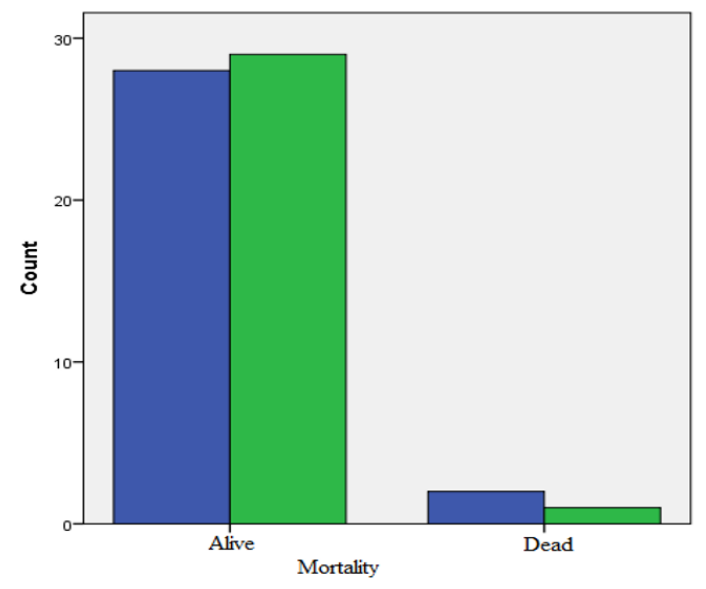

Monocusp valve

Transannular patch

Figure 4: Comparison of mortality rates in study groups. Patient mortality rates was low over 6 months, and both surgeries had a significant effect on keeping patients alive.

echocardiographic studies, MVs have also exhibited various morphologies. Some have been further attached to PA wall and were non-functional; however, other MVs have been fixated to the middle of RVOT. It was hypothesized that the immobile MVs fixed to the middle of the RVOT might have acted as an antiregurgitation device, prolonging the interval between initial TOF repair and PR aggravation. However, this mechanism still needs to be elucidated ${ }^{16}$.

Nevertheless, the main issue has been that synthetic materials for valve replacement cannot grow with children. For that reason, biological materials have been employed to reconstruct monocusp for pulmonary valve in order to preserve growth potential although progressive PR has been highlighted during follow-up periods ${ }^{20,23}$. Another study has suggested that it would be better to utilize a standby sparing technique to repair TOF because pulmonary leaflet sparing does not result in significant PR in post-TOF repair and tricuspid repair could protect against future developments of tricuspid regurgitation ${ }^{20}$. 
In this study, mortality rates were low in both groups. It should be noted that RV abnormality is a major element of morbidity and mortality following surgical repair of $\mathrm{TOF}^{24}$. This is justifiable since preserving RV functioning via preventing the right ventriculotomy reduces complications after TOF corrective surgery. The total correction of TOF through a transarterialtransventricular approach for patients aged greater than 6 months has also had a mortality rate of 0 $2 \%{ }^{24}$.

\section{CONCLUSION}

It was concluded that MV reconstruction of TOF is effective in mitigating PR. However, long-term reviews are needed to evaluate the surgical effects on ventricular dysfunction and to confirm these findings. As limitations, long-term follow-up and surgical complications were not evaluated in this study.

\section{ABBREVIATIONS}

ACT: Activated clotting time

ARDS: Acute respiratory distress syndrome

AVSD: Atrioventricular septal defect

CPB: Cardiopulmonary bypass

EF: Ejection fraction

FAC: Fractional area change

LV: Left ventricular

LVP: Left ventricular pressure

MPA: Main pulmonary artery

MVOP: Monocusp ventricular outflow patch

PAI: Pulmonary artery index

PI: Pulmonary valve insufficiency

PICU: Pediatric intensive care unit

PR: Pulmonary regurgitation

PV: Pulmonary valve

PVA: Pulmonary valve annulus

RV: Right ventricular

RVH: Right ventricular hypertrophy

RVOT: Right ventricular outflow tract

RVP: Right ventricular pressure

TAPE: Transannular patch enlargement

TAPSE: Tricuspid annular plane systolic excursion

TOF: Tetralogy of fallot

VAS: Visual Analogue Scale

VSD: Ventricular septal defect

\section{ACKNOWLEDGMENTS}

This article is adopted from the thesis fulfilled by Sayeh Haj Javadi as a Paediatric Resident, and also approved and funded by the Vice-Chancellor's Office for Research and Technology at Tabriz University of Medical Sciences, Iran. The researchers would like to extend one's gratitude to the Vice-Chancellor's Office for Research and Technology at Tabriz University of Medical Sciences and appreciate the staff members of Shahid Madani Hospital for their contribution to this study.

\section{AUTHOR'S CONTRIBUTIONS}

All authors made substantial contributions to conception and design, acquisition of data, or analysis and interpretation of data; took part in drafting the article or revising it critically for important intellectual content; gave final approval of the version to be published; and agree to be accountable for all aspects of the work.

\section{FUNDING}

The present study was financially supported by Tabriz University of Medical Sciences, Tabriz, Iran.

\section{AVAILABILITY OF DATA AND MATERIALS}

Data and materials used and/or analysed during the current study are available from the corresponding author on reasionable request.

\section{ETHICS APPROVAL AND CONSENT TO PARTICIPATE}

This study was conducted in accordance with the amended Declaration of Helsinki. The institutional review board approved the study, and all participants provided written informed consent.

\section{CONSENT FOR PUBLICATION}

Not applicable.

\section{COMPETING INTERESTS}

The authors declare that they have no competing interests.

\section{REFERENCES}

1. Gunduz E, Gorgel A, Dursun R, Durgun HM, Cil H, Icer M, et al. A Case of Uncorrected Tetralogy of Fallot Undiagnosed Until Adulthood and Presenting With Polycythemia. Cardiology research. 2014;5(6):198. PMID: 28352455. Available from: https://doi.org/10.14740/cr374e.

2. O'Brien P, Marshall AC. Tetralogy of Fallot. Circulation. 2014;130(4):e26-e9. Available from: https://doi.org/10.1161/ CIRCULATIONAHA.113.005547.

3. Gott VL. C. Walton Lillehei and total correction of tetralogy of Fallot. The Annals of thoracic surgery. 1990;49(2):328-332. Available from: https://doi.org/10.1016/0003-4975(90)901675.

4. Choi KH, Sung SC, Kim H, Lee HD, Ban GH, Kim, et al. A novel predictive value for the transannular patch enlargement in repair of tetralogy of Fallot. The Annals of thoracic surgery. 2016;101(2):703-707. PMID: 26718857. Available from: https: //doi.org/10.1016/j.athoracsur.2015.10.050. 
5. Aydın S, Suzan D, Temur B, Kırat B, Iyigün M, Demir IH, et al. The impact of pulmonary valve-sparing techniques on postoperative early and midterm results in tetralogy of Fallot repair. Turkish Journal of Thoracic and Cardiovascular Surgery. 2018;26(3). PMID: 32082766. Available from: https://doi.org/ 10.5606/tgkdc.dergisi.2018.15499.

6. Bigras JL, Boutin C, McCrindle BW, Rebeyka IM. Shortterm effect of monocuspid valves on pulmonary insufficiency and clinical outcome after surgical repair of tetralogy of Fallot. The Journal of thoracic and cardiovascular surgery. 1996;112(1):33-37. Available from: https://doi.org/10.1016/ S0022-5223(96)70175-7.

7. Mizuno A, Niwa K. The problems related with primary repair for tetralogy of Fallot, especially about transannular patch repair. Translational pediatrics. 2017;6(1):8. PMID: 28164024. Available from: https://doi.org/10.21037/tp.2016.06.05.

8. Wankhade PR, Aggarwal N, Joshi RK, Agarwal M, Joshi R, Mehta $A$, et al. Short-term clinical and echocardiographic outcomes after use of polytetrafluoroethylene bicuspid pulmonary valve during the repair of tetralogy of Fallot. Annals of pediatric cardiology. 2019;12(1):25. PMID: 30745766 . Available from: https://doi.org/10.4103/apc.APC_51_18.

9. Egbe AC, Mittnacht AJ, Nguyen K, Joashi U. Risk factors for morbidity in infants undergoing tetralogy of fallot repair. Annals of pediatric cardiology. 2014;7(1):13. PMID: 24701079. Available from: https://doi.org/10.4103/0974-2069.126539.

10. Sarris GE, Comas JV, Tobota Z, Maruszewski B. Results of reparative surgery for tetralogy of Fallot: data from the European Association for Cardio-Thoracic Surgery Congenital Database. European Journal of Cardio-Thoracic Surgery. 2012;42(5):766774. PMID: 23087090. Available from: https://doi.org/10.1093/ ejcts/ezs478.

11. Bouzas B, Kilner PJ, Gatzoulis MA. Pulmonary regurgitation: not a benign lesion. European heart journal. 2005;26(5):433439. PMID: 15640261 . Available from: https://doi.org/10.1093/ eurheartj/ehi091.

12. Brown JW, Ruzmetov M, Vijay P, Rodefeld MD. Turrentine MW Right ventricular outflow tract reconstruction with a polytetrafluoroethylene monocusp valve: a twelve-year experience. The Journal of thoracic and cardiovascular surgery. 2007;133(5):1336-1343. PMID: 17467453. Available from: https://doi.org/10.1016/j.jtcvs.2006.12.045.

13. Park CS, Lee JR, Lim HG, Kim WH, Kim YJ. The long-term result of total repair for tetralogy of Fallot. European Journal of Cardio-Thoracic Surgery. 2010;38(3):311-317. PMID: 20346688. Available from: https://doi.org/10.1016/j.ejcts.2010. 02.030 .

14. Kaza AK, Lim HG, Dibardino DJ, Bautista-Hernandez V, Robinson J, Allan C, et al. Long-term results of right ventricular outflow tract reconstruction in neonatal cardiac surgery: options and outcomes. The Journal of thoracic and cardiovascular surgery. 2009;138(4):911-916. PMID: 19660342. Available from: https://doi.org/10.1016/j.jtcvs.2008.10.058.

15. Feng W, Yao J, Yang $X$, Chu Z, Guo M, Wang L, et al. An in vitro study of the influence of monocusp patch size on the hemo- dynamics for reconstructing right ventricular outflow tract in tetralogy of Fallot. 2017 39th Annual International Conference of the IEEE Engineering in Medicine and Biology Society (EMBC). IEEE. 2017;Available from: https://doi.org/10.1109/ EMBC.2017.8037070.

16. Jang WS, Cho JY, Lee JU, Lee Y. Surgical results of monocusp implantation with transannular patch angioplasty in tetralogy of fallot repair. The Korean journal of thoracic and cardiovascular surgery. 2016;49(5):344. PMID: 27733993. Available from: https://doi.org/10.5090/kjtcs.2016.49.5.344.

17. Sasson L, Houri S, Sternfeld AR, Cohen I, Lenczner O, Bove EL, et al. Right ventricular outflow tract strategies for repair of tetralogy of Fallot: effect of monocusp valve reconstruction. European Journal of Cardio-Thoracic Surgery. 2012;43(4):743751. PMID: 23024233. Available from: https://doi.org/10.1093/ ejcts/ezs479.

18. Cowgill LD, Campbell DN, Kelminson L, Clarke DR. Repair of pulmonary valve insufficiency using an autologous monocusp. The Annals of thoracic surgery. 1986;42(5):587-589. Available from: https://doi.org/10.1016/S0003-4975(10)605929.

19. He GW. A new technique of transannular monocusp patchrepair of the right ventricular outflow tract in repair of tetralogy of Fallot. Heart, Lung and Circulation. 2007;16(2):107112. PMID: 17314068. Available from: https://doi.org/10.1016/ j.hlc.2006.10.013.

20. Arafat AA, Elatafy EE, Elshedoudy $S$, Zalat $M$, Abdallah $N$, Elmahrouk $A$. Surgical strategies protecting against right ventricular dilatation following tetralogy of Fallot repair. Journal of cardiothoracic surgery. 2018;13(1):14. PMID: 29357937. Available from: https://doi.org/10.1186/s13019-018-0702-0.

21. Sasikumar D, Sasidharan B, Tharakan JA, Dharan BS, Mathew T, Karunakaran J. Early and 1-year outcome and predictors of adverse outcome following monocusp pulmonary valve reconstruction for patients with tetralogy of Fallot: a prospective observational study. Annals of pediatric cardiology. 2014;7(1):5. PMID: 24701078. Available from: https://doi.org/ 10.4103/0974-2069.126538.

22. Turrentine MW, McCarthy RP, Vijay P, Fiore AC, Brown JW. Polytetrafluoroethylene monocusp valve technique for right ventricular outflow tract reconstruction. The Annals of thoracic surgery. 2002;74(6):2202-2205. Available from: https: //doi.org/10.1016/S0003-4975(02)03844-4.

23. Sen DG, Najjar M, Yimaz B, Levasseur SM, Kalessan B, Quaegebeur JM, et al. Aiming to preserve pulmonary valve function in tetralogy of Fallot repair: comparing a new approach to traditional management. Pediatric cardiology. 2016;37(5):818825. PMID: 26921062. Available from: https://doi.org/10.1007/ s00246-016-1355-1.

24. Sun G, Wang X, Chen J, Ma R, Li F, Chen L, et al. Primary repair of tetralogy of Fallot in infants: transatrial/transpulmonary or transventricular approach. Asian journal of surgery. 2013;36(4):137-143. PMID: 24054755. Available from: https: //doi.org/10.1016/j.asjsur.2013.01.005. 